\title{
A model study of the effects of climatic precipitation changes on ground temperatures
}

\author{
Xiaohua Lin, ${ }^{1}$ Jason E. Smerdon, ${ }^{2}$ Anthony W. England, ${ }^{1}$ and Henry N. Pollack ${ }^{3}$ \\ Received 23 August 2002; revised 10 January 2003; accepted 22 January 2003; published 15 April 2003.
}

[1] Temperature changes at the Earth surface propagate into the subsurface and leave a thermal signature in the underlying soil and rock. Inversions of subsurface temperature measurements yield reconstructions of ground surface temperature (GST) histories that provide estimates of climatic changes. A question remaining in the interpretation of reconstructed GST histories is the extent to which GST changes reflect changes principally in surface air temperature (SAT), or whether other factors may be significant. Here we use a Land Surface Processes (LSP) model to examine the influence of precipitation changes on GST and subsurface temperature and moisture fields on annual to decadal timescales. We model soil and vegetation conditions representative of a prairie region in the southern Great Plains of North America and force the model with meteorological data synthesized from a typical year in the region. Model responses are observed after changes in the amount of daily precipitation, the intensity and frequency of daily precipitation, and the diurnal and seasonal timing of precipitation. We show that: (1) increasing daily precipitation cools mean annual GST, (2) increasing the intensity and reducing the frequency of daily precipitation, while holding the annual amount of precipitation constant, cools mean annual GST, and (3) shifting maximum precipitation to occur in the warmest months cools mean annual GST. We compare modeled results to observed precipitation changes during the 20th century and conclude that the observed precipitation changes would cause only small changes to GST within the modeled region, on the order of $0.1 \mathrm{~K}$ or less. INDEX TERMS: 3322 Meteorology and Atmospheric Dynamics: Land/ atmosphere interactions; 1878 Hydrology: Water/energy interactions; 3354 Meteorology and Atmospheric Dynamics: Precipitation (1854); 1866 Hydrology: Soil moisture; 1875 Hydrology: Unsaturated zone;

KEYWORDS: SVAT model, subsurface temperatures, surface processes

Citation: Lin, X., J. E. Smerdon, A. W. England, and H. N. Pollack, A model study of the effects of climatic precipitation changes on ground temperatures, J. Geophys. Res., 108(D7), 4230, doi:10.1029/2002JD002878, 2003.

\section{Introduction}

[2] Many climatically important processes occur at the ground surface: absorption and reflection of solar radiation; absorption, reflection, and emission of thermal infrared radiation; partitioning of available moisture among infiltration, evaporation, vegetative transpiration, and runoff; conduction and advection of sensible heat within the soil, vegetation, and air; chemical weathering; and biological processes. The cumulative effect of these processes governs the heat flux at the ground surface and couples surface air temperature (SAT) with the temperature and heat content of shallow soils. During the last several centuries, and particularly between 1950 and 2000, warming of the ground

\footnotetext{
${ }^{1}$ Department of Atmospheric, Oceanic and Space Sciences, University of Michigan, Ann Arbor, Michigan, USA.

${ }^{2}$ Applied Physics Program, University of Michigan, Ann Arbor, Michigan, USA.

${ }^{3}$ Department of Geological Sciences, University of Michigan, Ann Arbor, Michigan, USA.
}

Copyright 2003 by the American Geophysical Union. 0148-0227/03/2002JD002878 surface has caused a positive heat gain in the upper part of the continental lithosphere commensurate with the heat gained by the other major components of the climate system [Beltrami et al., 2002; Beltrami, 2002]. Such changes in the heat content of the subsurface are observed in boreholes as temperature perturbations to background steady state temperature profiles. These temperature perturbations have been used extensively for reconstructing regional and global histories of the ground surface temperature (see Pollack and Huang, 2000, for a review).

[3] The basic premise underlying geothermal reconstructions of ground surface temperature (GST) is that temperatures at the ground surface establish a time-dependent temperature boundary condition, the effects of which propagate into the soil by thermal conduction. General agreement between such reconstructed GST histories and historical SAT records has been widely documented at various spatial scales [e.g., Huang et al., 2000, Harris and Chapman, 2001; Beltrami and Harris, 2001], and has given credence to the notion that GST reconstructions convey the generalized climatic history of a region. Energy transport at the Earth surface, however, clearly involves more than conductive coupling between the atmosphere and the soil; the down- 
ward propagating climate signal is the integrated result of complex surface processes that establish GST over time.

[4] Two complementary avenues of investigation contribute to the understanding of the coupling of air and ground temperatures. The first comprises high quality observational data, and the second utilizes numerical models of the processes active at the land-surface and in the subsurface. Long-term historical time series of SAT and precipitation at various timescales provide data relevant to how temperatures in the ground evolve. Soil temperatures at shallow depths have also been measured in a few places over decadal timescales [e.g., Baker and Ruschy, 1993; Schmidt et al., 2001; Zhang et al., 2001]. The relationships that have been deduced between meteorological records and ground temperatures are generally empirical correlations, and not focused primarily on process. Numerical models complement the observational investigations, and enable detailed and controlled simulations of processes via quantitative descriptions of coupled energy and moisture transport processes across the ground-atmosphere boundary [e.g., Sellers et al., 1997]. Here we employ the Land Surface Processes (LSP) model developed earlier by one of the authors (AWE) and his colleagues and students, for the purpose of understanding the links between the moisture content in the upper vadose zone of prairie regions, and the microwave brightness signal observed by satellites [England, 1990; Judge et al., 1997, 1999; Liou, 1996; Liou and England, 1996, 1998a, 1998b; Liou et al., 1999]. The model has been consistently improved and extensively tested and calibrated in the field since its early development [Galantowicz, 1995; Kim and England, 1998; Judge and England, 1999; Judge et al., 1998]. We use the LSP model with an extended lower boundary and many more layers in the subsurface to explore the effects of ground-atmosphere processes upon mean annual GST and shallow subsurface temperature and moisture fields.

[5] Specifically, we examine the effects of precipitation changes on GST in a prairie grassland setting, where the average daily SAT rarely goes below freezing. Thus the term precipitation in this context refers principally to rainfall. We investigate GST changes that result from changes in (1) the amount and intensity of daily precipitation, (2) the intensity and frequency of daily precipitation, while holding the amount of annual precipitation constant, and (3) the annual and diurnal timing of precipitation, while holding all other annual precipitation characteristics constant. In addition to GST responses we explore the accompanying changes in soil moisture content within the vadose zone, latent and sensible heat fluxes at the ground surface, and soil temperatures $20 \mathrm{~m}$ into the subsurface. Our results are presented as an illustration of method, and place bounds on some of the primary effects that precipitation can have on GST in the setting we have modeled. This study is the first in a series of investigations into the connections between microphysical ground-atmosphere processes, occurring on short timescales, and the downward propagating geothermal climate signal.

\section{The LSP Model}

\subsection{General Description}

[6] The LSP model estimates temporal temperature and moisture profiles, latent and sensible heat fluxes, the mag-
Table 1. Assigned Canopy Characteristics Within the LSP Model

\begin{tabular}{lc}
\hline Canopy Property & Assigned Value \\
\hline Vegetative Cover & $50 \%$ \\
Leaf Area Index & $3.5 \mathrm{~m}^{2} / \mathrm{m}^{2}$ \\
Vegetative Height & $0.7 \mathrm{~m}$ \\
Root Depth & $0.25 \mathrm{~m}$ \\
\hline
\end{tabular}

nitude and direction of moisture flow and changing soil characteristics throughout the entire modeled depth column. It incorporates surface albedo and roughness, snow cover, vegetation, soil moisture and thermo-physical properties, subsurface heat and moisture transport mechanisms, and freezing and thawing processes.

[7] The model is one-dimensional, comprising a multilayered soil with a two-layer vegetative canopy. The canopy consists of a layer of grass, with variable coverage between 0 and $100 \%$, overlying a thin layer of thatch. The grass layer links the canopy with the atmosphere through exchanges of energy and moisture. The lower thatch is an insulating layer that is subject to radiation exchanges with the upper canopy, the underlying soil and the atmosphere. The primary canopy properties we have used to model prairie grassland are shown in Table 1.

[8] The soil is modeled in 51 discrete layers, with the thickness of the layers increasing exponentially with depth. Conservation of mass and energy link the exchange between layers, and coupled energy and moisture transport establish the temperature and moisture profiles of the ground and canopy [Phillip and de Vries, 1957]. Sensible and latent heat exchanges are modeled as described in Liou et al. [1999]. The temperature and moisture content of the soil and canopy layers are solved simultaneously using a finite difference code at two-minute time steps.

[9] The lower boundary of the model can be set at any depth. Here we extend the model to $20 \mathrm{~m}$, and assign an insulating (i.e., zero heat flux) boundary condition at that depth. This thermal boundary condition excludes the outward flux of heat from the deeper interior of the Earth, and confines climatic disturbances to the overlying $20 \mathrm{~m}$ layer. Later models will extend the lower boundary to greater depths to observe the effects of surface processes on deeper subsurface temperature fields, but here we confine our attention principally to changes in GST taking place at the upper boundary of the model. Continuous hydrologic saturation (the water table) has been set at $3 \mathrm{~m}$. The consequences of the thermal and hydrologic boundary conditions are discussed later in the context of our experimental results.

[10] Thermal and hydrological properties of the soil layers are assigned and vary with depth, but also change with temperature and moisture content during model simulations. The two-parameter junction model developed by Rossi and Nimmo [1994] is used to compute the soil moisture retention curve and hydraulic conductivity. Heat capacity and thermal conductivity, as functions of soil temperature and moisture, are computed following the method used by de Vries [1963]. Three principal layers of soil characteristics have been assigned. These layers occur between 0.0 and $0.3 \mathrm{~m}, 0.3$ and $0.5 \mathrm{~m}$, and 0.5 and $20 \mathrm{~m}$. The significant characteristics of each layer, necessary for the calculation of variables such as thermal conductivity that 
Table 2. Constitutive Properties of Soil Layers Assigned Within the LSP Model

\begin{tabular}{ccccc}
\hline Layer & $\begin{array}{c}\text { Porosity, } \\
\mathrm{m}^{3} / \mathrm{m}^{3}\end{array}$ & $\begin{array}{c}\text { Ratio of Clay in } \\
\text { Dry Soil, } \\
\mathrm{m}^{3} / \mathrm{m}^{3}\end{array}$ & $\begin{array}{c}\text { Ratio of Quartz in } \\
\text { Dry Soil, } \\
\mathrm{m}^{3} / \mathrm{m}^{3}\end{array}$ & $\begin{array}{c}\text { Saturated } \\
\text { Hydraulic } \\
\text { Conductivity, } \\
\mathrm{m} / \mathrm{s}\end{array}$ \\
\hline $0-0.3 \mathrm{~m}$ & 0.48 & 0.225 & 0.775 & $4.74 \times 10^{-6}$ \\
$0.3-0.5 \mathrm{~m}$ & 0.38 & 0.225 & 0.775 & $4.74 \times 10^{-7}$ \\
$0.5-20 \mathrm{~m}$ & 0.28 & 0.225 & 0.775 & $4.74 \times 10^{-8}$ \\
\hline
\end{tabular}

change as temperature and moisture content in the soil change, are shown in Table 2.

\subsection{Forcings}

[11] The model is forced from above by downwelling short- and long-wave radiation, SAT, humidity, wind speed and precipitation. Downwelling radiation is estimated using the latitude-specific algorithm described by England [1990] based on the climatic SAT annual cycle, a fixed atmospheric water content, and constant cloud cover of $20 \%$. Relative humidity and wind velocity were held constant at values of $50 \%$ and $5 \mathrm{~m} / \mathrm{s}$, respectively. The LSP model is not a fully coupled ground-atmosphere exchange model, and therefore changes in atmospheric relative humidity at times of precipitation, or the coupling between evapotranspiration, wind and relative humidity cannot be included.

[12] The SAT and precipitation data used to force the model were obtained from the U.S. National Climate Data Center. We have focused on a southern prairie region in the state of Kansas, USA, because (1) the daily mean SAT rarely goes below freezing, and therefore cryogenic processes and effects are minimal, (2) the site is located within the Great Plains region of North America where the LSP grasslands model is relevant, (3) the precipitation characteristics are representative of the Great Plains region, and (4) the area is located where annual precipitation amounts change rapidly from the wetter East to the drier West on the North American continent, making significant local precipitation changes more likely during periods of climatic change.

[13] The LSP model, as its name suggests, has its principal focus on what happens at the ground surface and within the soil and rock beneath that surface, in response to external meteorological forcings. Such a model is not a fully coupled model in which the atmosphere also responds to changes at the ground surface; in the LSP model SAT and GST are implicitly independent and dependent variables, respectively. Such a simplification of the processes and exchanges at the ground surface has been a common feature of ground-atmosphere models for many decades [see, e.g., Kahle, 1977].

[14] To represent the seasonal SAT cycle, an annual sinusoid was fit to the average daily SAT measured during 1999 at Coldwater, Kansas $\left(37^{\circ} 16^{\prime} \mathrm{N}, 99^{\circ} 20^{\prime} \mathrm{E}\right)$. The annual mean air temperature of the approximated annual cycle was $15.4^{\circ} \mathrm{C}$ with an annual maximum of $26.5^{\circ} \mathrm{C}$ and an annual minimum of $4.2^{\circ} \mathrm{C}$. A diurnal oscillation was added to the SAT record, with an amplitude equal to the average difference between the maximum and minimum daily SAT. The diurnal temperature range was $6.9^{\circ} \mathrm{C}$. The approximated annual SAT time series is shown in Figure 1.

\subsubsection{Changes in Precipitation}

[15] We now turn particularly to the forcing associated with precipitation. The annual amount of precipitation at the Kansas site was $655 \mathrm{~mm}$. Most precipitation occurred between April and June, with the maximum monthly precipitation of $125 \mathrm{~mm}$ occurring in June (see Figure 1). The precipitation during each two-minute time step in the model was approximated by dividing daily precipitation evenly into each time step on the day of occurrence.

[16] Experiments that explore the effects of precipitation changes on GST are a central focus of this paper. We present three classes of experiments, each involving a permanent change in precipitation only; all other meteorological forcings, constitutive properties, and model characteristics remained unchanged. We focus on four important characteristics of precipitation: amount, intensity, frequency, and timing. The annual amount of precipitation is the sum of all daily precipitation events that occur during the year. The intensity of the precipitation record is a measure of the amount of precipitation occurring within a given period of time. Here we focus on the amount of precipitation per day and define an extreme event as any event above the 90th percentile ranking of daily precipitation amounts in the baseline record (greater than $31 \mathrm{~mm} /$ day). We define the frequency of events to be the number of daily events that occur during the year, that is, high frequency patterns have many daily precipitation events. The timing of precipitation is considered on both an annual and diurnal scale and is defined simply as the time period when precipitation occurs.

\subsection{Soil Moisture}

[17] Precipitation is of direct significance to the subsurface thermal regime because it changes the amount of soil

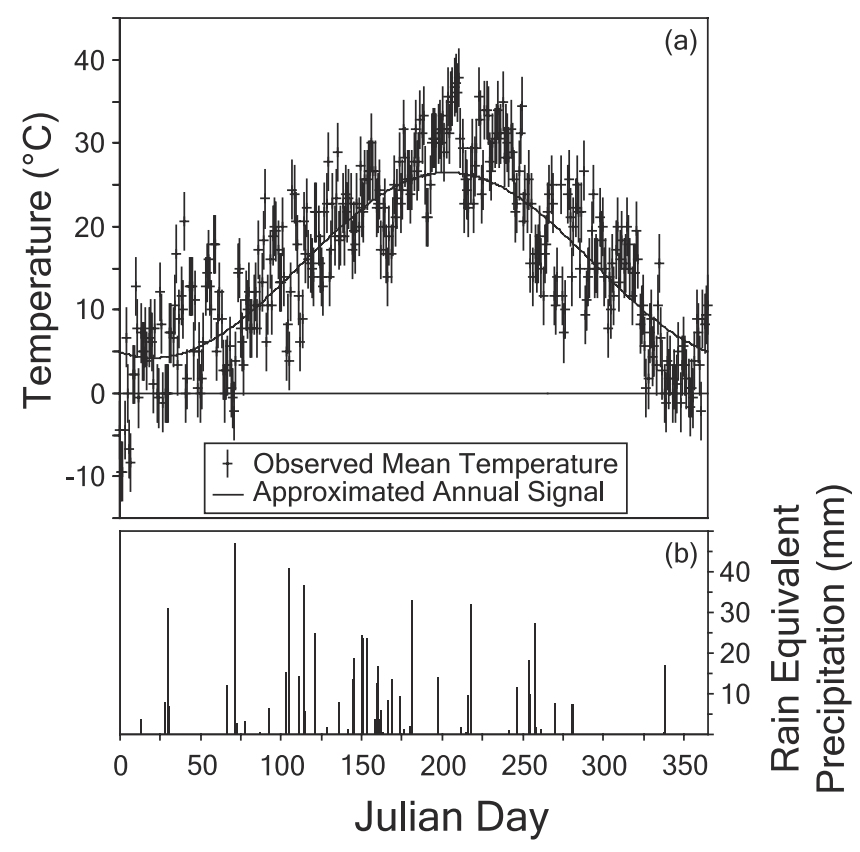

Figure 1. Daily SAT and precipitation records used to establish baseline model equilibrium. (a) Measured average daily SAT where vertical crosshairs are the daily average temperature range of $6.9^{\circ} \mathrm{C}$; the approximated annual SAT signal is shown as a solid black line. (b) Daily precipitation events. 


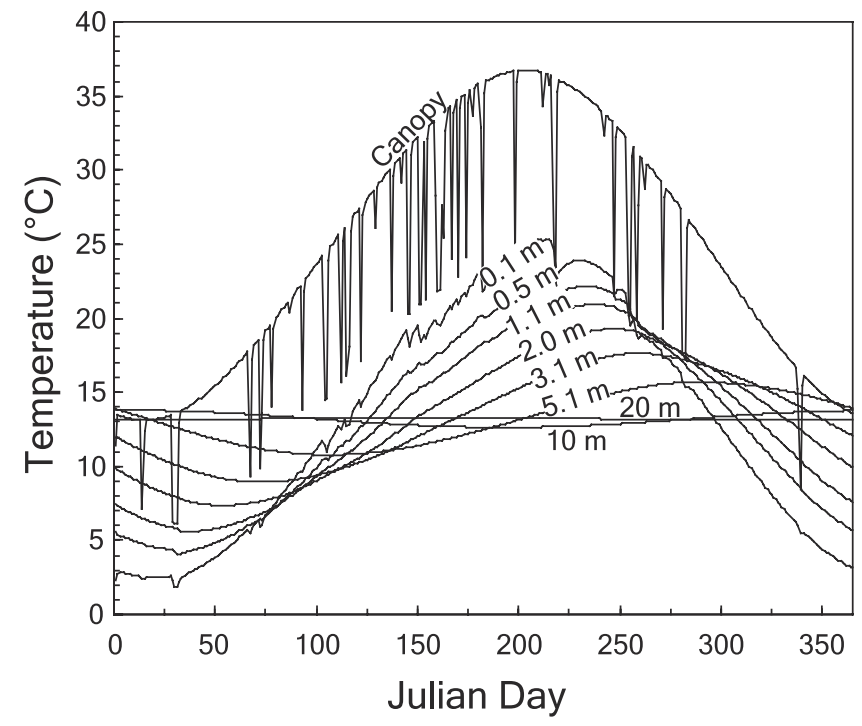

Figure 2. Daily average canopy and ground temperature time series at various depths during the baseline equilibrium period.

moisture, a soil property with direct influence on the amount of energy removed from the soil via latent and sensible heat fluxes. Secular changes in the amount, intensity, frequency, or the timing of precipitation influences the characteristics of infiltration that in turn affect rates of evapotranspiration and recharge; the net consequence is a change in the balance of latent and sensible heat fluxes at the ground surface. Shifts in the heat flux balance cause changes to GST, creating thermal imbalances that are communicated downward into the subsurface.

[18] We analyze soil moisture changes based on changes in infiltration, evaporation, transpiration and recharge fluxes over time. We consider a soil volume defined by a column of soil spanning the entire vadose zone. Infiltration is determined by the hydrologic properties of the soil and the difference between precipitation and the fraction of the water intercepted by the canopy. Runoff occurs during precipitation events when water reaches the soil surface at a rate that exceeds the rate of infiltration. No experiments within this study involve precipitation events that generate runoff. Because canopy characteristics remain constant on annual timescales and none of the experiments involve runoff, all changes in infiltration are caused by changes in precipitation. Evaporation and transpiration are both negative terms that remove moisture from the soil or canopy by vapor-phase transport of moisture into the atmosphere and plant root uptake and release of moisture into the atmosphere, respectively. We refer to the collective removal of moisture from the ground surface by the two processes as evapotranspiration. Recharge is defined as the flux of moisture at the water table boundary. This flux can be positive or negative depending on the direction of moisture flow at the boundary. Here we define positive recharge as moisture flow from the vadose zone into the phreatic zone, and negative recharge as flow occurring in the opposite direction. The annual sum of these fluxes is quantitatively small, and the effect on the depth to the water table is negligible.

\section{Experiments and Results}

\subsection{Baseline Equilibrium Experiments}

[19] The complete year of meteorological forcings described in section 2.2 was repeated 40 times to synthesize a long-term record of 40 years with no secular changes in any of the meteorological forcings. The 40 -year record was used to drive the LSP model at two-minute time steps. Equilibrium within the model, recognized as the time when annual averages of heat and moisture profiles were no longer changing, was established during the first 40 years of simulation. The baseline equilibrium temperature and moisture time series during year 40 are shown at various depths in Figures 2 and 3a, respectively.

[20] The annual temperature signals in Figure 2 display characteristic temperature attenuation and phase shift with depth [de Vries, 1963]. High frequency perturbations to the annual signal shown in Figure 2 are caused by precipitation events that change the moisture content of the soil, and consequently the latent and sensible heat fluxes at the ground surface. Figure 3b clearly indicates that the general influence of precipitation at daily timescales is to increase the latent heat flux and decrease the sensible heat flux.
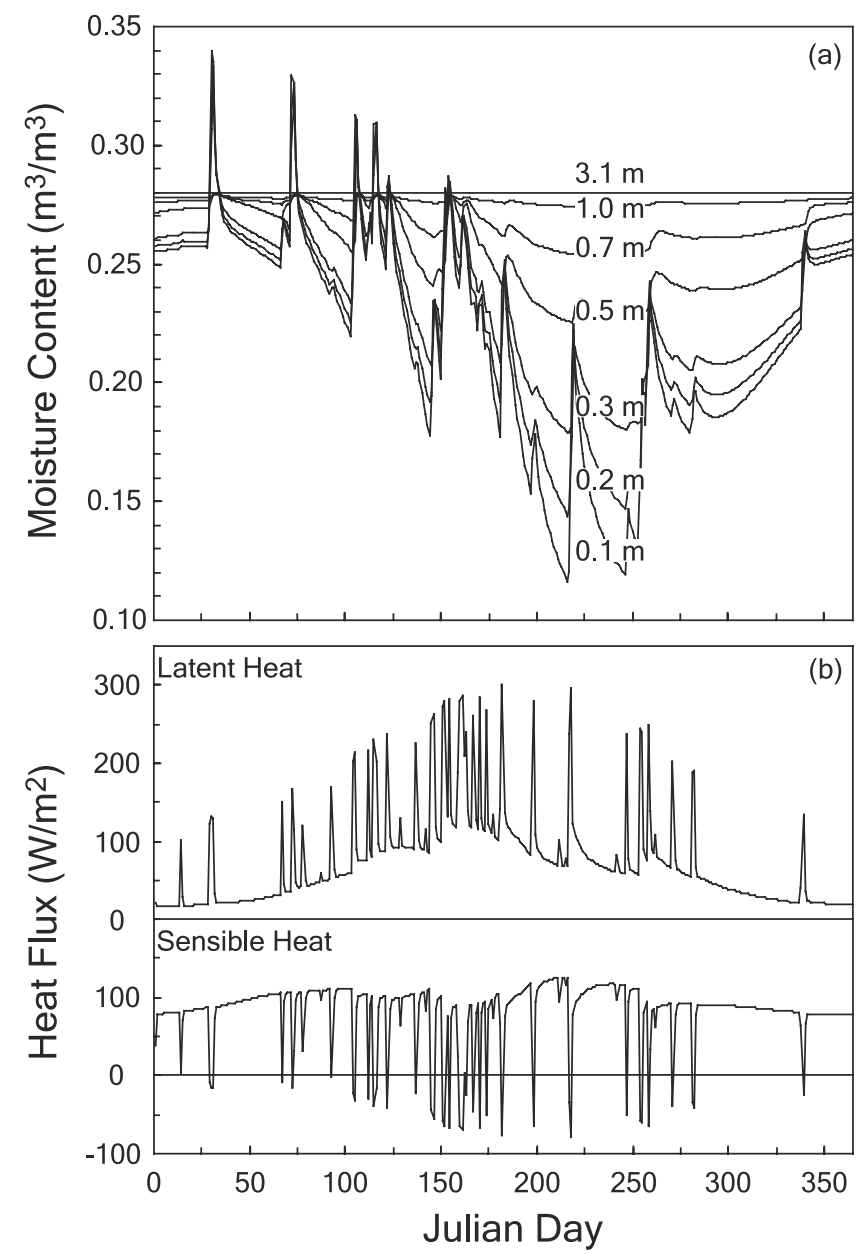

Figure 3. Baseline equilibrium calculations of (a) daily average moisture content at various depths and (b) daily average latent and sensible heat fluxes at the ground surface. Positive flux values correspond to heat fluxes out of the ground. 


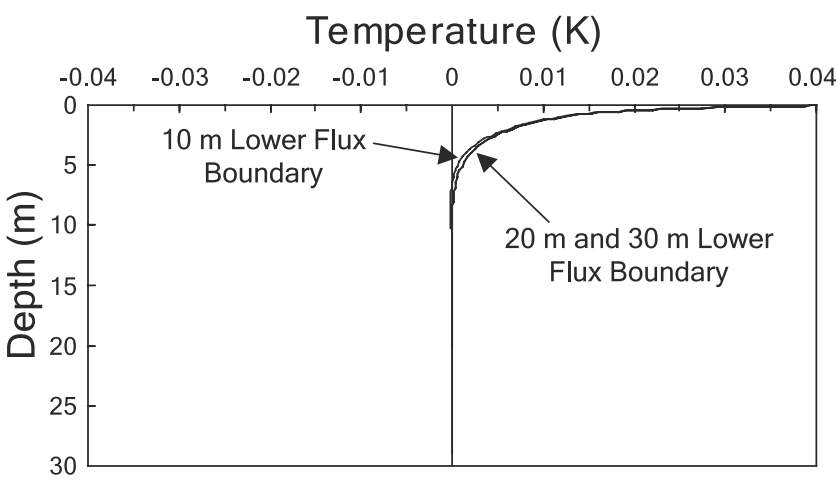

Figure 4. Equilibrium ground temperature profiles established with the insulating boundary condition set at 10, 20, and $30 \mathrm{~m}$. All of the ground temperatures have been plotted as anomalies away from the zero-gradient section of the temperature profile.

Figure 2 also indicates that the high frequency perturbations to ground temperatures caused by precipitation attenuate completely within the upper several meters of the subsurface. The seasonal variation in soil moisture evident in Figure $3 \mathrm{a}$ also illustrates the strong seasonal influence of the radiation and SAT cycles on soil moisture and is consistent with other experimental observations in regions of the North American Great Plains [e.g., Robock et al., 2000; Choudhury, 2000].

\subsection{Lower Boundary Condition Experiment}

[21] The effect of the insulated lower boundary condition was tested to determine how the location of the boundary affected equilibrium conditions. Figure 4 shows annual averages of three equilibrium temperature profiles established by placing the heat flux boundary at 10,20, and $30 \mathrm{~m}$. In each of the three cases, the GST and the zero gradient section of the equilibrium temperature profile were not affected by the location of the lower boundary. Some of the equilibrium temperatures at intermediate depths did change depending on the boundary choice, but the differences are negligible; moreover, we do not use the temperatures at any of the intermediate depths in a quantitative analysis. The principal consequence of a shallow flux boundary is the acceleration of ground temperature responses to climate perturbations; the time taken to achieve equilibrium increased as the lower boundary was moved to greater depths. Equilibrium was established after 20, 40, and 80 years of simulation when the lower boundary was set at 10,20 , and $30 \mathrm{~m}$, respectively. The shallow insulated lower boundary does not allow the development of the deeper climate signal, but it does allow model simulations to proceed to equilibrium much more rapidly; at the same time it has no influence on the development of the GST at the upper boundary of the model. Thus, we have performed all simulations with an insulating boundary condition at $20 \mathrm{~m}$.

\subsection{Precipitation Experiments}

[22] Permanent, systematic and controlled alterations to the baseline precipitation record were made after the 40year spin-up period. The annual equilibrium temperature and moisture profiles established at the end of the first 40 years of simulation were used as a baseline for comparison to subsequent changes in ground temperature and soil moisture content after precipitation changes were imposed at the beginning of the 41 st year. Equilibrium comparisons were made 40 years after precipitation changes occurred, by which time annual temperature and moisture profiles once again had achieved stasis. We discuss each of the simulated changes to the precipitation record and the consequences for ground conditions in the sections that follow.

\subsubsection{Precipitation Amount and Intensity}

[23] The first class of experiments changed the amount and intensity of precipitation by scaling daily precipitation events by factors of $0.5,0.75,1.25,1.5,1.75$, and 2.0. Table 3 lists the principal changes in precipitation characteristics caused by these scaling modifications. Scaling daily precipitation events by factors greater than unity caused an increase in the amount of annual precipitation and in the intensity of daily events. The percentage of extreme events increased by $5 \%$ and $18 \%$ after daily precipitation was scaled by 1.25 and 2.0 , respectively. Scaling daily precipitation events by factors less than unity caused the amount of annual precipitation and the intensity of daily events to decrease. No extreme events occurred after applying a scaling factor of 0.5 ; after daily precipitation was scaled by 0.75 extreme events were reduced by $8 \%$. In all of the scaling experiments the frequency and timing of the precipitation record were not changed.

Table 3. Amount, Intensity, and Frequency Statistics for the Baseline and Modified Precipitation Records

\begin{tabular}{|c|c|c|c|c|c|}
\hline Experiment & $\begin{array}{c}\text { Precipitation Amount, } \\
\mathrm{mm} / \mathrm{yr}\end{array}$ & $\begin{array}{c}\text { Number of Events, } \\
\text { days }\end{array}$ & $\begin{array}{c}\text { Percentage of } \\
\text { Precipitation } \\
\text { Events Above the } \\
\text { 90th Percentile } \\
\text { in the Baseline } \\
\text { Precipitation Record, } \\
>31 \mathrm{~mm} / \text { day }\end{array}$ & $\begin{array}{c}\text { Percentage of } \\
\text { Precipitation } \\
\text { Events Below the } \\
\text { 10th Percentile } \\
\text { in the Baseline } \\
\text { Precipitation Record, } \\
<1.3 \mathrm{~mm} \text { /day }\end{array}$ & $\begin{array}{c}\text { Standard Deviation } \\
\text { of Daily Events } \\
\text { away from the } \\
\text { Mean Daily } \\
\text { Precipitation } \\
\text { of Each Record, } \\
\text { mm } \\
\end{array}$ \\
\hline Baseline & 655 & 53 & 10 & 10 & 6.2 \\
\hline 2.0 Scale & 1310 & 53 & 28 & 6 & 6.2 \\
\hline 1.75 Scale & 1146 & 53 & 25 & 6 & 6.2 \\
\hline 1.5 Scale & 983 & 53 & 21 & 8 & 6.2 \\
\hline 1.25 Scale & 819 & 53 & 15 & 8 & 6.2 \\
\hline 0.75 Scale & 491 & 53 & 2 & 17 & 6.2 \\
\hline 0.5 Scale & 328 & 53 & 0 & 23 & 6.2 \\
\hline Increased Standard Deviation & 655 & 29 & 35 & 7 & 8.2 \\
\hline Decreased Standard Deviation & 655 & 201 & 0 & 33 & 2.6 \\
\hline Uniform Drizzle & 655 & 365 & 0 & 100 & 0.0 \\
\hline
\end{tabular}



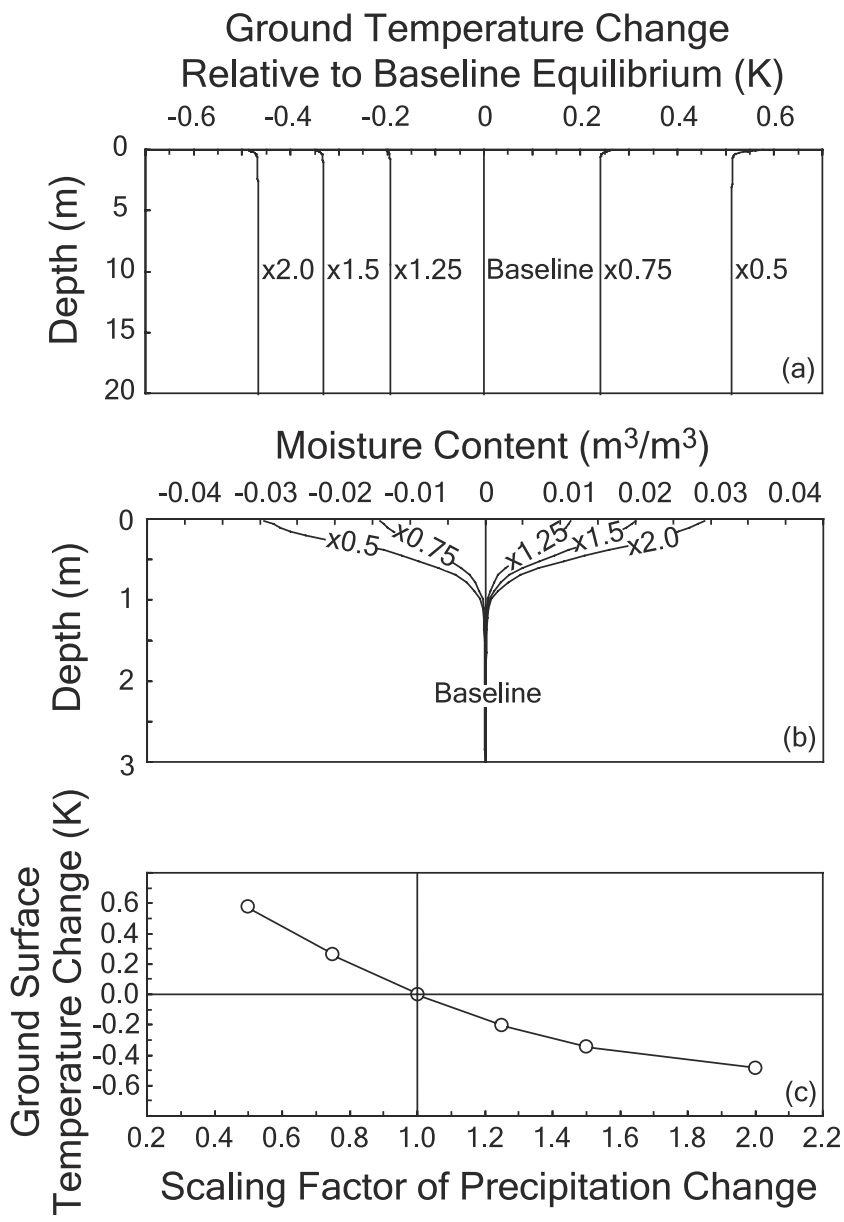

Figure 5. Responses in ground temperature and soil moisture content after daily precipitation events were scaled by factors ranging from 0.5 to 2.0 . (a) Temperature profile changes relative to baseline. (b) Moisture content changes relative to baseline. (c) GST changes relative to baseline as a function of scaling factor.

[24] Increases in the amount and intensity of daily precipitation cause a cooling and wetting within the subsurface; decreases cause the ground to warm and dry. The effects on temperature profiles and on moisture profiles down to the water table are shown in Figures 5a and 5b, respectively. The GST, relative to baseline equilibrium, is shown as a function of the scaling factor in Figure $5 \mathrm{c}$. The maximum GST cooling of $0.49 \mathrm{~K}$ was caused by a $100 \%$ increase in the amount of daily precipitation; a $50 \%$ decrease in daily precipitation caused a maximum GST warming of $0.58 \mathrm{~K}$.

[25] The responses in ground temperature and soil moisture content to increasing scaling factors shown in Figure 5 are attributed to two changes in precipitation characteristics. First, scaling the daily precipitation upward increases the amount of moisture within the soil. Second, the enhanced precipitation intensity caused by increasing scaling factors reduces the fraction of intercepted moisture and prolongs moisture storage in the upper soil layers. Both responses increase moisture availability within the near-surface soil layers, and cause increases in the average annual latent heat flux and decreases in the average annual sensible heat flux. These effects are amplified in the upper meter of the soil

where the greatest changes in soil moisture occur, and lead to the marked curvature of the profile of temperature changes (relative to the baseline) in the upper meter, as shown in Figure 5a. Figure 6a displays annual averages of latent and sensible heat fluxes as a function of the scaling factor and confirms their dependence on soil moisture content. The net heat flux at the ground surface, also shown in Figure 6a, indicates an enhanced net heat loss at the ground surface with increasing scaling factor, a response that is consistent with the ground temperature changes highlighted in Figure 5. By similar arguments, decreases in precipitation amounts and intensities cause warming in the ground.

\subsubsection{Precipitation Intensity and Frequency}

[26] In the second class of experiments the precipitation record was filtered either to enhance or reduce the intensity and frequency of daily precipitation while holding the

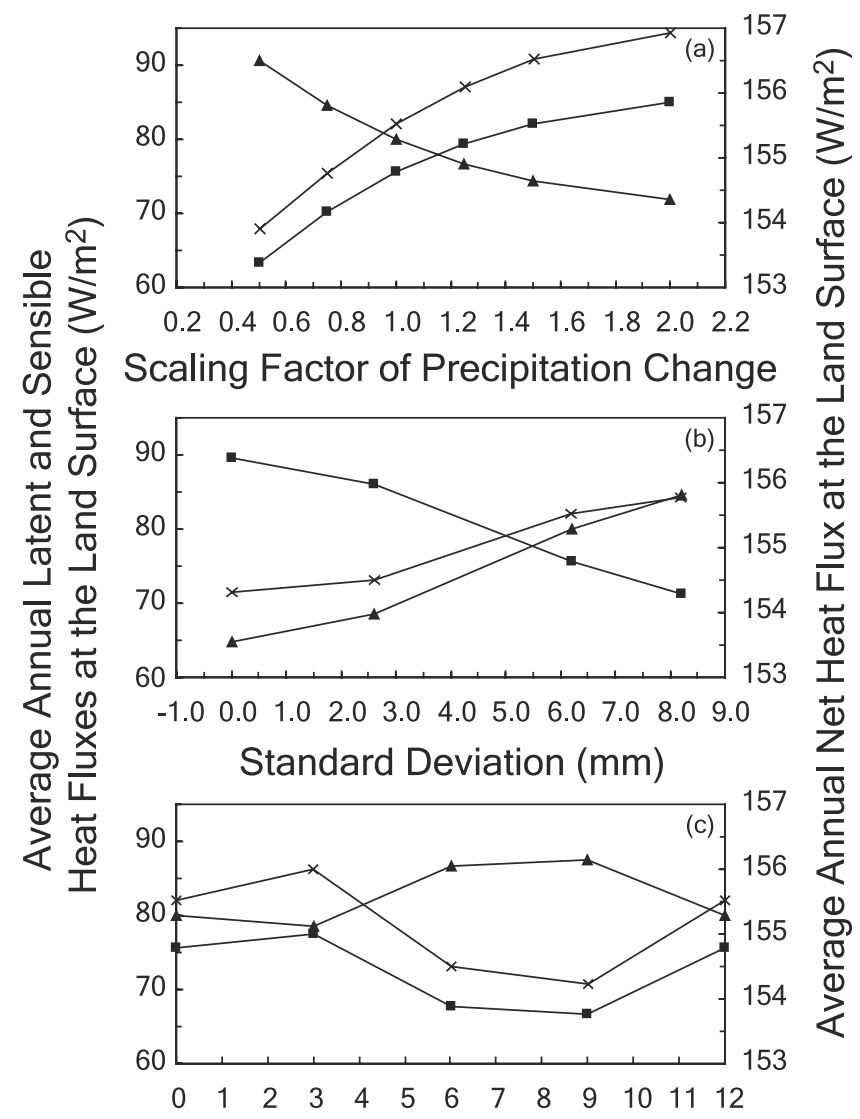

Time Shift in Precipitation Record (months)

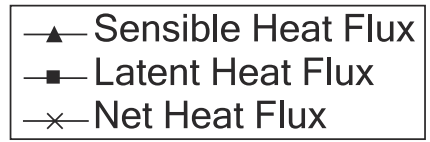

Figure 6. Changes in the annual average sensible heat flux, latent heat flux and their sum (latent and sensible heat fluxes are plotted along the left ordinate and their sum is plotted along the expanded right ordinate) at the ground surface boundary after permanent changes in (a) the scaling of daily precipitation events, (b) the intensity and frequency of daily precipitation events, and (c) the seasonal timing of precipitation. All annual fluxes are positive and correspond to heat fluxes out of the ground. 


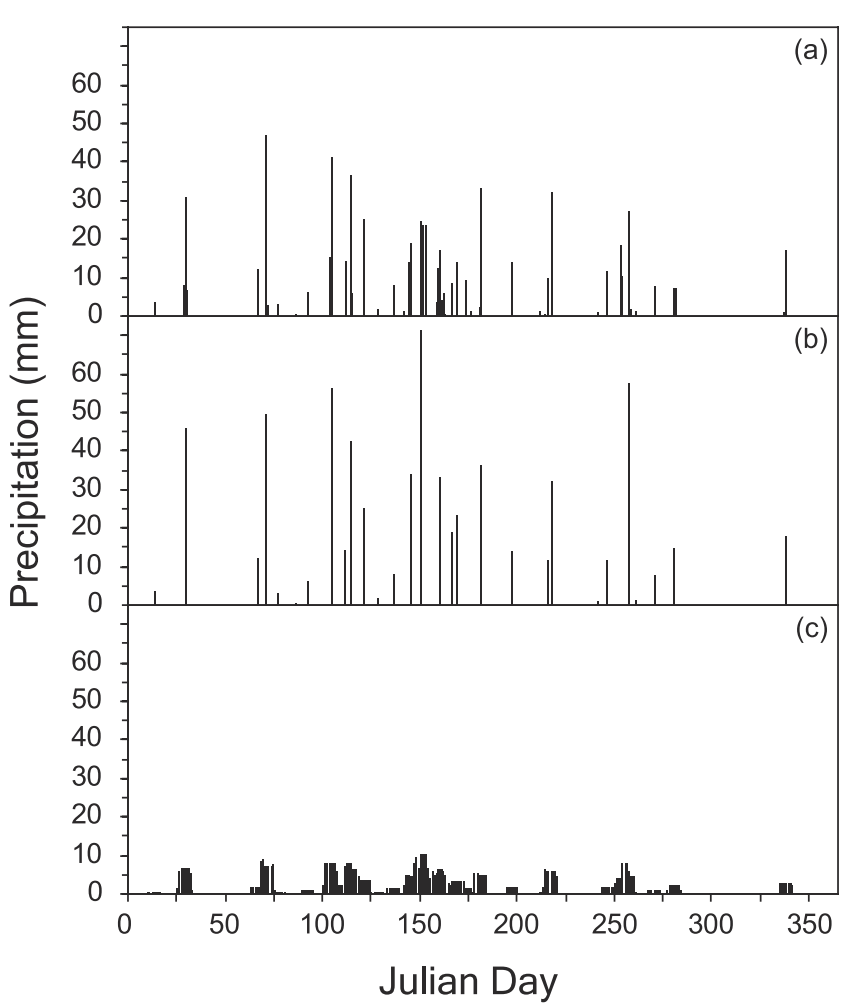

Figure 7. (a) Precipitation record used to establish baseline equilibrium. (b) Altered precipitation record where daily intensity has increased and daily frequency has decreased. (c) Altered precipitation record where daily intensity has decreased and daily frequency has increased.

amount of annual precipitation constant. As a standard measure of the filtering process, we quantified the changes in the precipitation record as the change in the standard deviation of daily precipitation amounts away from the daily mean of the annual record. The standard deviation of the baseline precipitation record was $6.2 \mathrm{~mm}$. The first modification of the record was accomplished by dividing the total annual precipitation evenly into each day of the year to achieve a constant daily drizzle. Consequently, the new standard deviation was zero, the frequency of daily events increased to 365 events per year, all daily magnitudes were within the lowest 10th percentile of the baseline record, and the daily precipitation was $1.8 \mathrm{~mm}$. The second modification applied a centered boxcar filter to the precipitation record so as to distribute precipitation during seven-day periods uniformly over each day of the period. This filtering technique reduced the standard deviation of the original record to $2.6 \mathrm{~mm}$, increased the frequency of events to 201 days per year, and eliminated all extreme events from the record. To increase the intensity of the record, all of the precipitation occurring within seven-day periods was changed to occur on the day that originally had the maximum precipitation amount within each period. Following these redistributions, the standard deviation of the precipitation record changed to $8.2 \mathrm{~mm}$, the frequency of events was reduced to 29 days per year, and the percentage of extreme events increased by $25 \%$ above the baseline. The original and filtered precipitation records are shown in Figure 7 (excluding a plot of the constant daily drizzle), and Table 3 contains all of the statistics pertaining to precipitation changes in the second class of experiments.

[27] Increasing the intensity of daily precipitation while decreasing the frequency causes the ground to cool and soil moisture to increase, whereas reduced intensity and enhanced frequency lead to warming and drying of the ground. The effects of intensity and frequency on subsurface temperature and moisture profiles are shown in Figures $8 \mathrm{a}$ and $8 \mathrm{~b}$, respectively. Changes in the GST as a function of standard deviation are shown in Figure 8c. An increase in intensity and decrease in frequency, as measured by a standard deviation increase of $2 \mathrm{~mm}$, causes the GST to cool by $0.07 \mathrm{~K}$. A standard deviation decrease of $3.6 \mathrm{~mm}$, or a decrease in the intensity and increase in the frequency, caused the GST to warm by $0.42 \mathrm{~K}$. A change to continuous daily drizzle, equivalent to a standard deviation decrease of $6.2 \mathrm{~mm}$, causes a GST warming of $0.69 \mathrm{~K}$.

[28] Decreasing precipitation intensity causes a larger fraction of precipitation to be intercepted by the canopy.
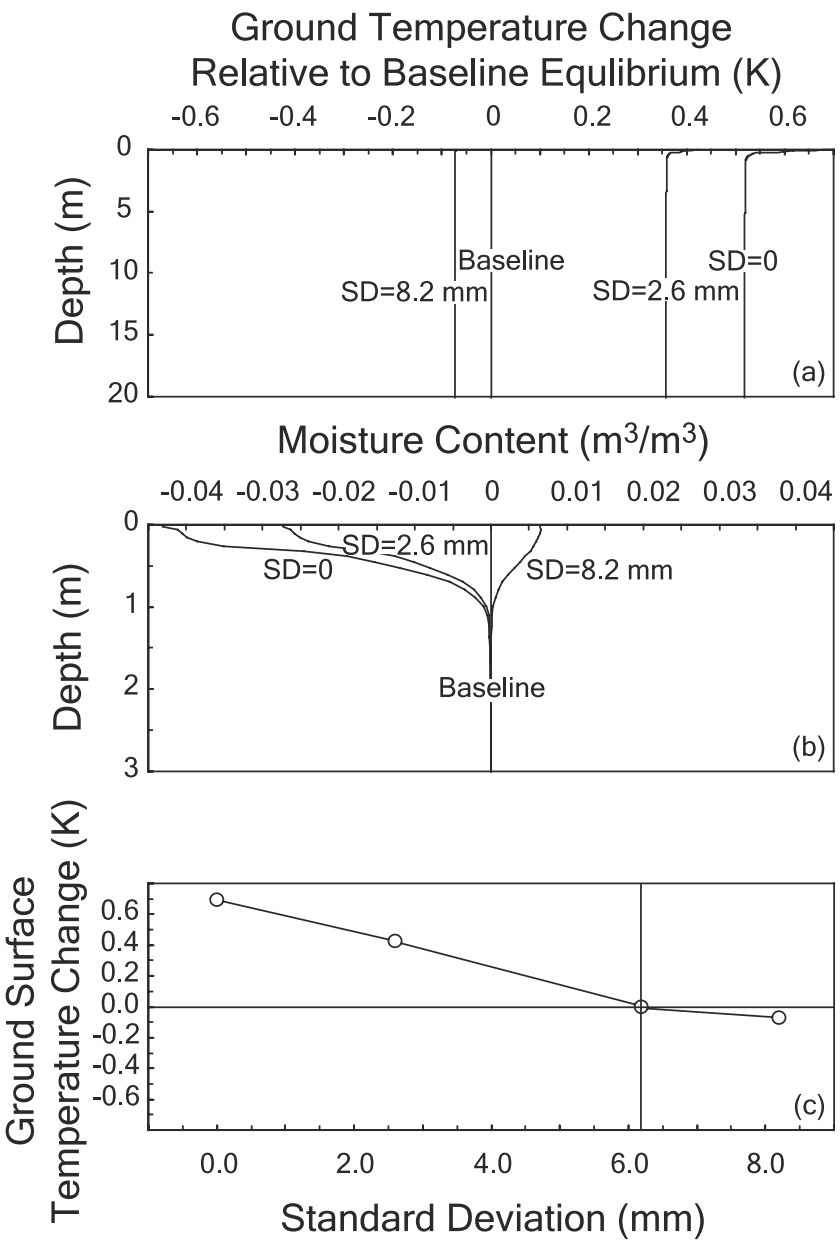

Figure 8. Responses in ground temperature and soil moisture content after the standard deviation of daily precipitation events in the annual record were changed between 0 and $8.2 \mathrm{~mm}$. (a) Temperature profile changes relative to baseline. (b) Moisture content changes relative to baseline. (c) GST changes relative to baseline as a function of the standard deviation of daily events within the annual record. 
Under such circumstances, latent heat fluxes at the ground surface increase (see Figure $6 \mathrm{~b}$ ) because intercepted moisture evaporates more rapidly than moisture stored in the soil. In turn, evaporating more of the intercepted moisture fraction reduces the amount of moisture reaching the soil surface and causes drier soil conditions (note the trend in Figure $8 b$ ). Thus, unlike the scaling experiments where intensity increases were also accompanied by increased amounts of precipitation, latent heat fluxes were inversely tied to GST and the net heat flux at the ground surface because more energy is removed from air in the canopy. During precipitation events, this cooling of the air within the canopy warms the ground by reducing the temperature difference between the canopy and soil, consequently reducing the sensible heat flux at the ground surface. Changes in the sensible heat flux out of the ground become the dominant factors in determining the net heat flux and are shown in Figure 6b. The figure illustrates that the net heat flux follows the behavior of the sensible heat flux under the imposed conditions. Consequently, the ground temperatures shown in Figure 8 are governed by the changes in sensible heat flux at the ground surface.

\subsubsection{Diurnal and Seasonal Timing of Precipitation}

[29] The third class of experiments investigated the importance of the diurnal and seasonal timing of precipitation. Within the baseline simulation, daily precipitation was divided evenly into all twenty-four hours of the day that it occurred. Perturbations to the diurnal timing of precipitation were imposed by dividing daily precipitation amounts into time periods centered upon daytime $(6: 00$ am to $6: 00 \mathrm{pm})$ or nighttime hours $(6: 00 \mathrm{pm}$ to $6: 00 \mathrm{am})$, while all other features of the precipitation record were left unchanged. Shifting the precipitation record by three, six, and nine months, imposed seasonal changes in the occurrence of precipitation. The peak precipitation in the baseline record occurred between April and June. The imposed seasonal shifts caused approximate precipitation peaks in August, November, and February, respectively. Once again, the seasonal time shift was the only alteration to the precipitation record; the amount, intensity, and frequency of precipitation remained unchanged.

[30] Numerical experiments that contained only daytime or nighttime precipitation generated a GST that cooled by $0.17 \mathrm{~K}$ and $0.15 \mathrm{~K}$, respectively. The degree of cooling was approximately the same for both daytime and nighttime changes. This suggests that the timing of precipitation on diurnal scales is not significant in the generation of ground temperatures on longer timescales. However, both of the diurnal shifts caused cooling relative to baseline ground temperatures. As discussed in section 3.3.2, this is due to the increase in precipitation intensity caused by concentrating precipitation into either daytime or nighttime hours.

[31] Shifting the precipitation record on seasonal timescales allowed investigations into the relationship between annual precipitation peaks, seasonal radiation and SAT. During baseline equilibrium conditions the peak in the precipitation over the year did not coincide with maximums in radiation and SAT. The three months with the largest monthly precipitation were June, April, and May (ranked in descending order), whereas the maximums in radiation and SAT occurred during July. Thus, the available energy to drive evapotranspiration was not at a maximum during peak

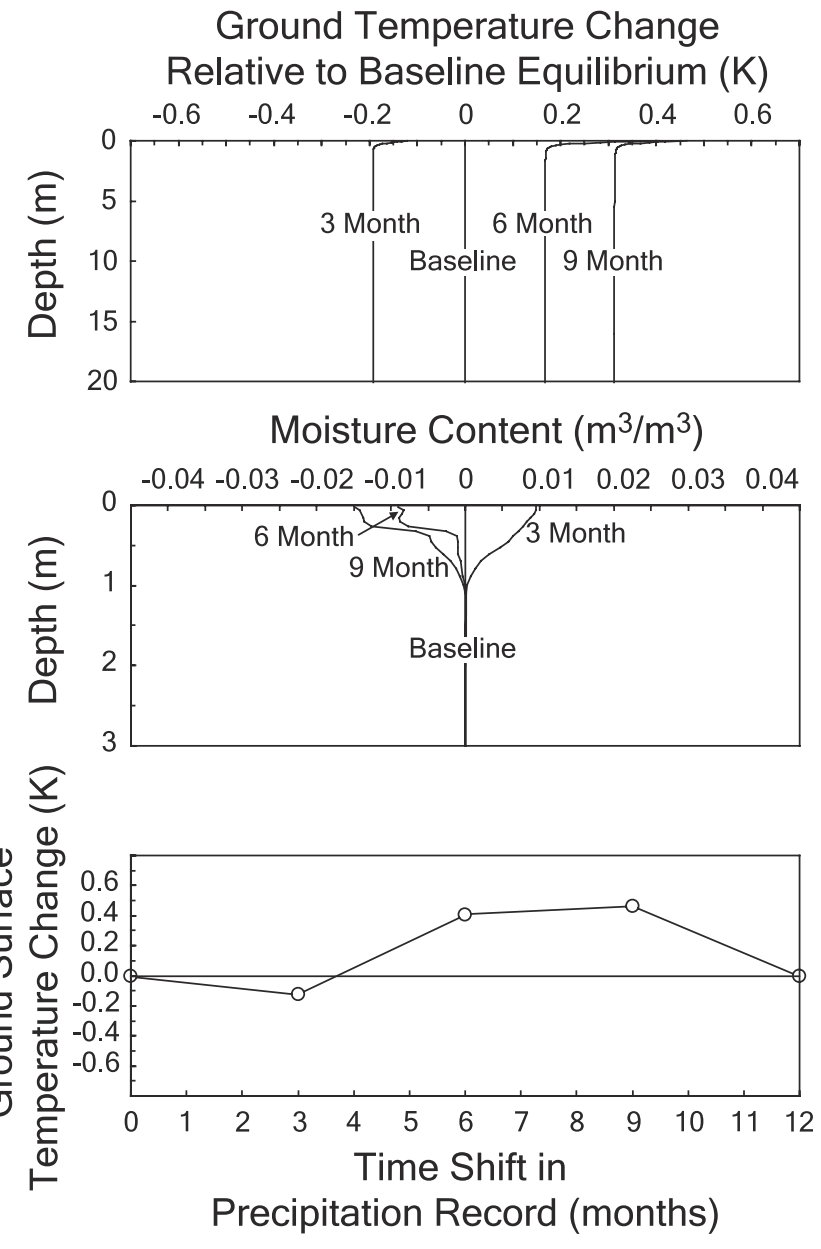

Figure 9. Responses in ground temperature and moisture responses after the annual phasing of the annual record was shifted between 0 and 12 months. (a) Temperature profile changes relative to baseline. (b) Moisture content changes relative to baseline. (c) GST changes relative to baseline as a function of time shift in the annual precipitation record.

precipitation. Ground temperature and moisture content profiles, after shifting precipitation by three, six, and nine months, are shown in Figures 9a and 9b. The corresponding GST changes are shown in Figure 9c. A maximum cooling of the GST by $0.12 \mathrm{~K}$ occurred after shifting precipitation by three months, where peak amounts aligned more closely with peak radiation levels. Bringing the precipitation peak progressively closer to the radiation minimum in January with six and nine month shifts caused GST warming, relative to baseline, by $0.40 \mathrm{~K}$ and $0.46 \mathrm{~K}$, respectively.

[32] The seasonal time shift experiments highlight the coupled influence of precipitation, seasonal radiation and SAT on daily latent and sensible heat fluxes at the ground surface. In the absence of radiation or SAT changes, moisture availability within the soil is the rate-limiting feature of latent heat flux and maximum levels occur only after precipitation events in the summer months. In a highly peaked precipitation pattern, shifting the seasonal peak to align with peak radiation and SAT causes maximum annual latent heat fluxes to occur. This seasonal dependence is shown in Figure $6 \mathrm{c}$, where a three-month shift of the precipitation pattern has aligned peak precipitation with 


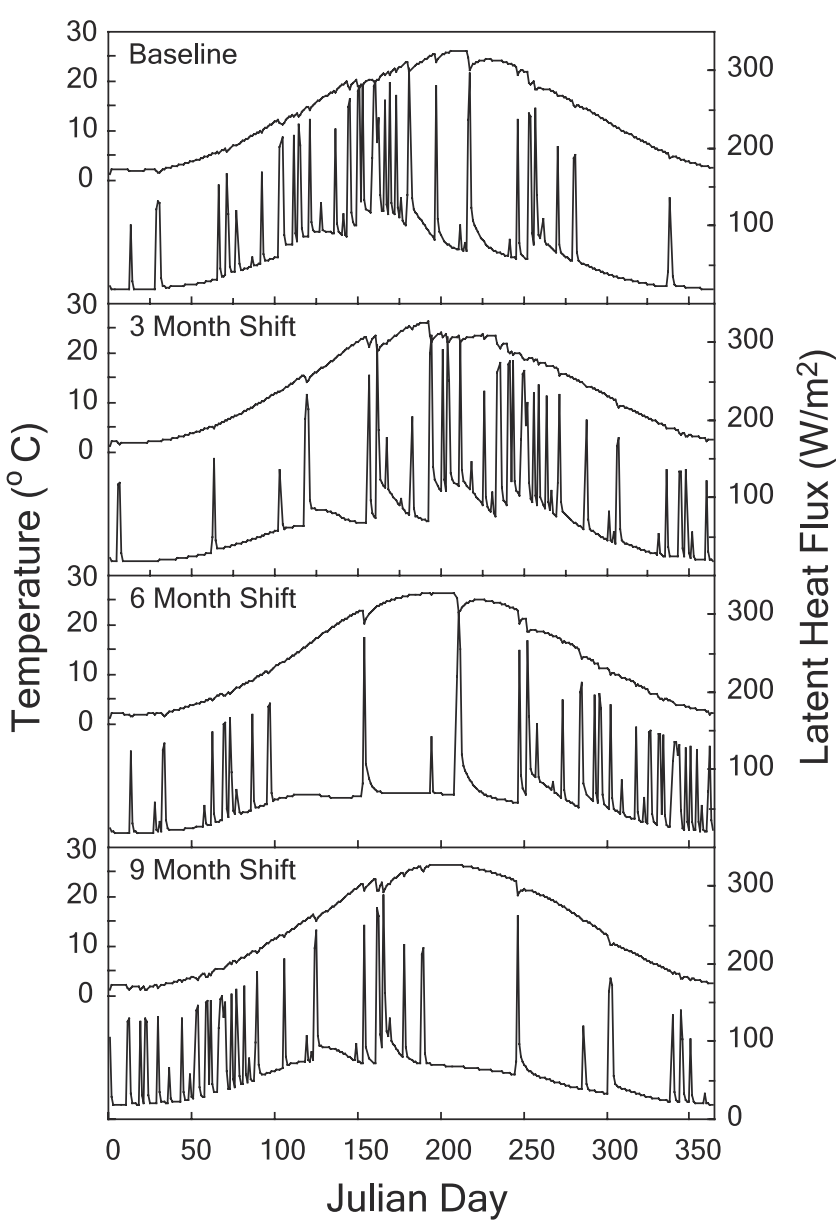

Figure 10. Ground surface temperature and latent heat flux time series in equilibrium during the baseline experiment and after 3-, 6-, and 9-month shifts in the precipitation record. Ground surface temperature time series is the upper series in each box and are plotted along the left ordinate, while latent heat fluxes are plotted along the right ordinate.

maximum radiation and SAT during the summer months, and caused the largest annual latent and net heat flux. The minimum annual latent and net heat fluxes, also shown in Figure 6c, occurred when precipitation peaked during winter months. Figure 10 is a complementary illustration showing the daily latent heat flux and GST for the baseline and time shifted equilibrium experiments. GST perturbations are very small during the winter and the seasonal character of the GST is not significantly changed by a winter concentration of precipitation. However, GST perturbations are relatively large during summer precipitation events and the maximum period of the GST cycle is visibly reduced when precipitation events are concentrated during the summer months.

[33] The increase in annual soil moisture with the increase in annual latent heat flux can seem counterintuitive when the annual amount of precipitation has not increased. However, the timing of precipitation also affects recharge rates. Positive recharge reaches maximum levels after precipitation events in the winter months when latent heat fluxes are low and soil moisture is high. When peak precipitation occurs during the winter much of the moisture is lost to the phreatic zone as positive recharge and causes drier annual soil conditions. Thus, the annual moisture profile is determined by a balance between large latent heat fluxes in the summer and large positive recharge rates in the winter. Under the conditions modeled here maximum moisture conditions occurred as described, but changes in the characteristics of the modeled regime, the location of the water table for instance, may change the way that maximum soil moisture coincides with the alignment of peaks in meteorological forcings.

\subsection{Some Caveats}

[34] Some meteorological conditions with seasonal variability have the potential to affect the results shown here. Relative humidity changes on both seasonal and diurnal scales, and influences the rate of evapotranspiration out of the soil. In all our experiments, however, we held humidity constant at a typical annual value. While the southern prairie region of Kansas does not have significant seasonal fluctuations in relative humidity, diurnal fluctuations can be on the order of tens of percent. We also held cloud cover constant, but in a real-world setting changes in cloud cover can significantly change the magnitude of the incoming solar radiation on diurnal and seasonal timescales. Wind speeds are also diurnally and seasonally variable with a variety of consequences, but we have maintained a constant wind speed in our experiments.

[35] The location of the water table affects the amount of moisture available within the vadose zone. Preliminary experiments have confirmed that changes in the location of the water table change the rate and flow of moisture at the water table boundary relative to baseline equilibrium values. Setting the location of the water table at depths greater than $3 \mathrm{~m}$ dries the upper layers of the soil somewhat. Nevertheless, we have not widely explored the influence of the location of this boundary on our results.

\section{Discussion}

[36] Measured precipitation increases within the United States during the 20th century have been approximately 5 to $10 \%$ [IPCC, 2001$]$ while precipitation in Canada has increased by an average of more than $10 \%$ during the same period [Mekis and Hogg, 1999]. The IPCC [2001] reports an increase between 0.5 to $1 \%$ /decade in the mid and high latitudes over much of the Northern Hemisphere (of which some, of course, occurs as snowfall). Areas have also shown precipitation decreases, for example subtropical land areas have observed decreases on the order of $0.3 \% /$ decade $[I P C C, 2001]$. All of these reported precipitation changes are smaller than the changes that we have imposed at a single time step within the LSP model. The smallest imposed scaling factor increase or decrease of $25 \%$ in our experiment, causing a GST change of approximately \pm 0.2 $\mathrm{K}$, is more than twice as large as the upper range of the estimates for North America or all of the Northern Hemisphere. Thus, a linear interpolation of our results suggests that GST responses to precipitation changes within the specific region of study would be less than $0.08 \mathrm{~K}$. Compared to observed GST and SAT changes of about $0.6 \mathrm{~K}$ during the 20th century, our results indicate that 
precipitation changes probably contributed to the observed changes in GST in only a small way.

[37] Changes in the occurrence of extreme precipitation events have also been documented by the IPCC. In the mid and high latitudes of the Northern Hemisphere during the latter half of the 20th century, the IPCC [2001] estimates that "it is likely that there has been a 2 to $4 \%$ increase in the frequency of heavy precipitation reported by the available observing stations." The IPCC [2001] has suggested that increases in the frequency of extreme events may go handin-hand with increases in the magnitude of annual precipitation and vice versa, but they have also reported that extreme events have increased in some regions where annual precipitation has decreased. Our results suggest that ground cooling is caused where precipitation intensity increases in a prairie grassland setting. We have observed the opposite for decreases in precipitation intensity. However, the changes we have imposed are much larger than observed changes. The smallest increase in precipitation intensity, while holding the total annual amount of precipitation constant, involved a $25 \%$ increase in the number of extreme events and caused the ground to cool by only $0.07 \mathrm{~K}$. This suggests that observed intensity increases alone would have a negligible effect on ground temperatures in the southern Great Plains. The combination of increases in precipitation magnitudes and extreme events, as suggested by the IPCC, would work constructively to cool the GST. This combination of changes was investigated by the scaling experiments, where increases in the amount of precipitation also involved intensity increases. Increasing daily precipitation amounts by $100 \%$ while increasing daily precipitation intensity by $18 \%$ caused the ground to cool by $0.49 \mathrm{~K}$. However, an intensity increase of $25 \%$ independent of an increase in the annual amount of precipitation only cooled the ground by $0.07 \mathrm{~K}$. Thus, increasing amounts of precipitation appear to influence ground temperature changes more significantly than intensity increases.

[38] Large seasonal shifts in the precipitation record caused the ground to warm or cool by several tenths of a degree. These simulated large seasonal shifts in the occurrence of precipitation are clearly not realistic. Karl and Knight [1998] show differences between the relative changes in seasonal precipitation within the United States on the order of several millimeters per year, but none of the differences would account for shifts as extreme as those imposed in our experiments. Nevertheless, the fundamental result is significant: the seasonal timing of precipitation affects the magnitude of energy and moisture fluxes at the ground-atmosphere boundary. This result suggests that assessments of the long-term interaction of air and ground that make use of only annual totals of precipitation may not fully capture the consequences of seasonal timing. The timing of the precipitation within the year has implications for ground-atmosphere interactions beyond those associated with the total amount of precipitation that occurred.

[39] We summarize the principal results of this study as follows:

[40] 1. Increases in the amount of rainfall cause annual GST to cool, whereas decreases cause annual GST to warm. Scaling daily precipitation upward by $100 \%$ and downward by $50 \%$ caused annual GST to decrease by $0.49 \mathrm{~K}$ or increase by $0.58 \mathrm{~K}$, respectively. Observed changes in the amount of precipitation during the 20th century, an increase of perhaps some $5-10 \%$, are much smaller than the range of precipitation changes we have investigated with the LSP model. This suggests that changes in the amount of precipitation may have decreased ground temperatures within the southern prairie region of North America by only $0.05-0.10 \mathrm{~K}$ over the century.

[41] 2. More extreme rainfall events cause annual GST to cool, while reducing the number of extreme events cause annual GST to warm. The effect of changes in precipitation intensity on annual GST, however, is very small; annual GST changed by only $0.07 \mathrm{~K}$ after a $25 \%$ percent increase in the number of extreme precipitation events. This increase in precipitation intensity is 5-10 times larger than observed changes during the 20th century.

[42] 3. Minimum annual GST will occur when peak seasonal precipitation coincides with peak seasonal radiation and SAT. Large changes in the seasonal timing of precipitation have the potential to change GST by $0.4-$ $0.5 \mathrm{~K}$. While this suggests that the seasonal timing of precipitation plays an important role in establishing energy and moisture fluxes at the ground surface, no significant changes in the timing of seasonal precipitation have been observed over the 20th, and therefore cannot have contributed to changes in annual GST.

\section{Concluding Remarks}

[43] We have illustrated a new method for investigating the influence of climate on subsurface temperature fields using high-fidelity numerical simulations of minute-byminute microphysical ground-atmosphere interactions over decadal timescales. Our results are generated from an a priori description of ground surface processes; we make no assumptions regarding the dominant mechanisms of energy transport within the ground. We suggest that continued investigation of ground-atmosphere interactions by means of the methods proposed here will help to elucidate the long-term effects of climatic change on the partitioning of heat into the subsurface. We have also provided an understanding of the influence of precipitation on subsurface temperature fields in prairie regions where cryogenic effects are minimal. We have shown that a variety of changes in precipitation occurring as rainfall can affect ground temperatures independent of other meteorological variables with static annual averages. Our model simulations place reasonable bounds on GST responses caused by precipitation changes. Observed precipitation changes during the 20th century are much smaller than the full range of precipitation changes we have examined, and lead us to conclude that effects on GST associated with long-term precipitation changes were likely small relative to the GST and SAT changes observed over the 20th century.

[44] Acknowledgments. This research has been supported by NSF Grant ATM-0081864, by the University of Michigan through Grant OVPR4237, and by the Department of Geological Sciences of the University of Michigan. We thank the reviewers for their thoughtful and helpful comments.

\section{References}

Baker, D. G., and D. L. Ruschy, The recent warming in eastern Minnesota shown by ground temperatures, Geophys. Res. Lett., 20(5), 371-374, 1993. 
Beltrami, H., On the relationship between ground temperature histories and meteorological records: A report on the Pomquet station, Global Planet Change, 29, 327-348, 2001.

Beltrami, H., Climate from borehole data: Energy fluxes and temperatures since 1500, Geophys. Res. Lett., 29(23), doi:10.1029/2002GL015702, 2002 .

Beltrami, H., and R. N. Harris (Eds.), Inference of climate change from geothermal data, Global Planet. Change, 29, 148-352, 2001.

Beltrami, H., J. E. Smerdon, H. N. Pollack, and S. Huang, Continental heat gain in the global climate system, Geophys. Res. Lett., 29(8), 1167, doi:10.1029/2001GL014310, 2002.

Choudhury, B. J., Seasonal and interannual variations of total evaporation and their relations with precipitation, net radiation, and net carbon accumulation for the Gediz basin area, J. Hydrol., 229, 77-86, 2000.

de Vries, D. A., Thermal properties of soils, in Physics of Plant Environment, edited by W. R. van Wijk, pp. 210-235, North-Holland, Amsterdam, 1963. England, A. W., Radiobrightness of diurnally heated, freezing soil, IEEE Trans. Geosci. Remote Sens., 28(4), 464-476, 1990.

Galantowicz, J. F., Field data report for the first radiobrightness energy balance experiment (REBEX-1), Oct. 1992-April 1993, Sioux Falls, SD, RL-193, Univ. of Mich. Rad. Lab., Ann Arbor, 1995.

Harris, R. N., and D. S. Chapman, Mid-latitude $\left(30^{\circ}-60^{\circ} \mathrm{N}\right)$ climatic warming inferred by combining borehole temperatures with surface air temperatures, Geophys. Res. Lett., 28(5), 747-750, 2001.

Huang, S., H. N. Pollack, and P. Y. Shen, Temperature trends over the last five centuries reconstructed from borehole temperatures, Nature, 403, $756-758,2000$

IPCC, Observed Climate Variability and Change, in Climate Change 2001: The Scientific Basis, edited by J. T. Houghton et al., pp. 100-181, Cambridge Univ. Press, New York, 2001.

Judge, J., and A. W. England, Field data report for the fourth radiobrightness energy balance experiment (REBEX-4): June-September 1996, RL974, Univ. of Mich. Rad. Lab., Ann Arbor, 1999.

Judge, J., J. F. Galantowicz, A. W. England, and P. Dahl, Freeze/Thaw classifications for prairie soils using SSM/I radiobrightness, IEEE Trans Geosci. Remote Sens., 35(4), 827-832, 1997.

Judge, J., A. W. England, B. K. Hornbuckle, D. L. Boprie, and E. J. Kim Field data report for the fifth radiobrightness energy balance experiment (REBEX-5), RL-964, Univ. of Mich. Rad. Lab., Ann Arbor, 1998.

Judge, J., A. W. England, W. L. Crosson, C. A. Laymon, B. K. Hornbuckle, D. L. Boprie, E. J. Kim, and Y.-A. Liou, A growing season land surface process/radiobrightness model for wheat-stubble in the southern Great Plains, IEEE Trans. Geosci. Remote Sens., 37(5), 2152-2158, 1999.

Kahle, A. B., A simple thermal model of the Earth's surface for geologic mapping by remote sensing, J. Geophys. Res., 82, 1673-1680, 1977.

Karl, T. R., and R. W. Knight, Secular trends of precipitation amount, frequency, and intensity in the United States, Bull. Am. Meteorol. Soc. $79,231-241,1998$
Kim, E. J., and A. W. England, Field data report for radiobrightness energy balance experiment 3 (REBEX-3), Sept. 1994-Sept. 1995 , Alaskan North Slope, $R L-918$, Univ. Mich. Rad. Lab., Ann Arbor, 1998

Liou, Y.-A., Land surface process/radiobrightness models for northern prairie, Ph.D. thesis, Univ. of Mich., Ann Arbor, 1996.

Liou, Y.-A., and A. W. England, Annual temperature and radiobrightness signatures for bare soils, IEEE Trans. Geosci. Remote Sens., 34(4), 981 990, 1996

Liou, Y.-A., and A. W. England, A land surface process/radiobrightness model with coupled heat and moisture transport in soil, IEEE Trans. Geosci. Remote Sens., 36(1), 273-286, 1998a.

Liou, Y.-A., and A. W. England, A land-surface process/radiobrightness model with coupled heat and moisture transport for freezing soils, IEEE Trans. Geosci. Remote Sens., 36(2), 669-677, 1998b.

Liou, Y.A., J. F. Galantowicz, and A. W. England, A land surface process radiobrightness model with coupled heat and moisture transport for prairie grassland, IEEE Trans. Geosci. Remote Sens., 37(4), 1848-1859, 1999.

Mekis, E., and W. D. Hogg, Rehabilitation and analysis of Canadian daily precipitation time series, Atmos. Ocean, 37(1), 53-85, 1999.

Phillip, J. R., and D. A. de Vries, Moisture movement in porous materials under temperature gradients, Eos Trans. $A G U, 38(2), 222-232$, 1957.

Pollack, H. N., and S. Huang, Climate reconstructions from subsurface temperatures, Ann. Rev. Earth Planet. Sci., 28, 339-365, 2000

Robock, A., K. Y. Vinnikov, G. Srinivasan, J. K. Entin, S. E. Hollinger, N. A. Speranskaya, S. Liu, and A. Namkhai, The Global moisture data bank, Bull. Am. Meteorol. Soc., 81(6), 1281-1299, 2000

Rossi, C., and J. Nimmo, Modeling of soil water retention from saturation to oven dryness, Water Resour. Res., 30(3), 701-708, 1994

Schmidt, W. L., W. D. Gosnold, and J. W. Enz, A decade of air-ground temperature exchange from Fargo, North Dakota, Global Planet. Change, $29,311-325,2001$

Sellers, P. J., et al., Modeling the exchanges of energy, water, and carbon between continents and the atmosphere, Science, 275, 502-509, 1997.

Zhang, T., R. G. Barry, D. Gilichinsky, S. S. Bykhovets, V. A. Sorokovikov, and J. Ye, An amplified signal of climatic change in soil temperatures during the last century at Irkutsk, Russia, Clim. Change, 49, 41-76, 2001 .

A. W. England and X. Lin, Department of Electrical Engineering and Computer Science, University to Michigan, 3124 EECS Building, Ann Arbor, MI 48109-2122, USA. (england@umich.edu; xiaohual@umich.edu)

H. N. Pollack and J. E. Smerdon, Department of Geological Sciences, University of Michigan, 2534 C.C. Little Building, Ann Arbor, MI 481091120,USA. (hpollack@umich.edu; jsmerdon@umich.edu) 